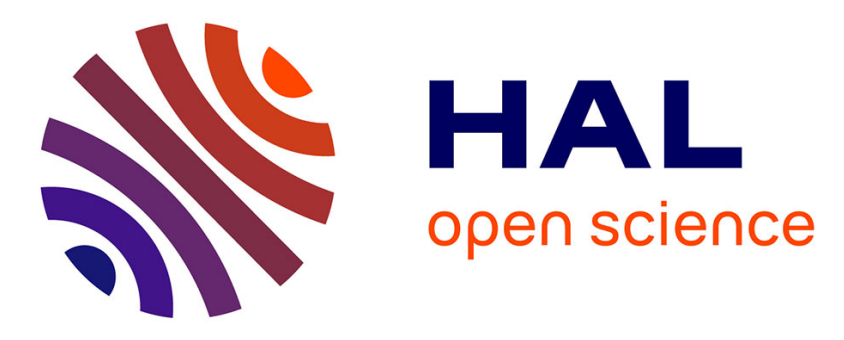

\title{
Reservoir compartmentalization and fluid property determination using a modular dynamic tester (MDT): case study of an Algerian oil field
}

H. Belhouchet, M. Benzagouta, A. Dobbi, E. Mazouz, N. Achi, Joelle Duplay, M. Khodja

\section{To cite this version:}

H. Belhouchet, M. Benzagouta, A. Dobbi, E. Mazouz, N. Achi, et al.. Reservoir compartmentalization and fluid property determination using a modular dynamic tester (MDT): case study of an Algerian oil field. Euro-Mediterranean Journal for Environmental Integration, 2021, 6 (1), 10.1007/s41207020-00216-5 . hal-03360538

\section{HAL Id: hal-03360538 \\ https://hal.science/hal-03360538}

Submitted on 4 Oct 2021

HAL is a multi-disciplinary open access archive for the deposit and dissemination of scientific research documents, whether they are published or not. The documents may come from teaching and research institutions in France or abroad, or from public or private research centers.
L'archive ouverte pluridisciplinaire HAL, est destinée au dépôt et à la diffusion de documents scientifiques de niveau recherche, publiés ou non, émanant des établissements d'enseignement et de recherche français ou étrangers, des laboratoires publics ou privés. 


\title{
Reservoir Compartmentalization and Fluid Properties Determination via Modular Dynamic Tester (MDT): An application for a Case study from an Algerian Oil Field
}

\author{
H. E. Belhouchet · M. S. Benzagouta - A. Dobbi · E. Mazouz · N. Achi · J. Duplay · M. Khodja.
}

\begin{abstract}
Reservoir compartmentalization identification and initial properties determination are key factors for any development of oil field aspects. These characteristics are largely serving for outlining the type and the number of reservoir fluids setting. They are expected to state initial reservoir pressure and reservoir potential. Assessing the potential fluid presence and its range, for each respective zone, comes to be essential. For the case study, the associated reservoirs consist of different respective borehole potentially effective zones where fluid limits remain ambiguous. The applied method in these commitments consists of exploiting recorded pressure using Modular Formation Dynamics Tester tools (MDT) to analyze the pressure gradients and variation. This device is intended to make real-time discrimination and split up between formation fluids. Objectives in that concern are also to define reservoir compartments based on the analytical analysis of pressure gradients, taking into account the reservoir fluid type. Aims in this investigation are conducted towards the identification of the reservoir initial conditions and the setting of the Free Water Level (F.W.L.) for each interesting zone. Thus, in that context, approach on reservoir heterogeneity can be a key factor.
\end{abstract}

Conducted analysis is related to an oilfield consisting of an anticlinal structure, located in the Saharan platform (South - Eastern of Algeria). This oilfield is part of Hassi Berkine basin. From a sedimentological point of view, the depositional environment has been found as fluvial-continental deposits. Some erosional impacts of the Hercynian discordance were present affecting essentially the top of the Frasnian clays. The main hydrocarbon reservoir consists of the Lower Shaly - Triassic Sandstone Formation (TAG-I): Current designation for the Sahara plateforem Triasic reservoir in the investigated area. This TAGI has been subdivided into three sub-levels: Upper TAGI (TAGI-U), Middle (TAGI-M) and the Lower (TAGI-L).

Obtained outcomes revealed several pressure gradients versus depth. According to obtained graphs, and statistically, these gradients elucidate, for the same considered borehole section, significant trends. Important to mention that a substantial difference in pressure was observed between the oilfield boreholes e.g. TAGI- U+M and TAGI-L. The equivalent density of these gradients displays a fluid deposit succession as; oil (TAGI-U+M), water (TAGI-M), and oil (TAGI-L). Lithologically, a stratigraphic barrier between TAGI U+M and TAGI-L has been identified. With a superimposed pressure gradients observed in the two wells ( 1 and 2), two reservoir compartments have been deduced. Furthermore, using pressure evolution versus depth as well as density record, for each reservoir communicated level; two free water levels (F.W.L.), in addition to the initial pressure, were identified.

\section{KEY-WORDS}

Porous medium, fluid types, Reservoir pressure, Mobility, Fluid contact.

\section{INTRODUCTION}

The fluid flow, in a porous medium, is a very complex phenomenon. Identification and selection of the most appropriate solutions must be required to define the main parameters related to the porous medium (Benzagouta, M.S. et al., 2001). Among these parameters are porosity and permeability. Based on literature reviews, several tools have been used to determine these parameters (O. Serra, 1984). Concerning formation porosity, it can be determined using methods such as laboratory core analysis via gas or water injection. Logging tools can support the obtained laboratory results for porosity 
evaluation. Among these devices, apte to record porosity are the Computed Tomography (CT), Neutron Density Logging (C.N.L), sonic tools $(\Delta \mathrm{t})$, Focused Density Log (FDC) and Nuclear Magnetic Resonance tools (NMR) (Hongqi Liu, 2017).

Many reviewers were approaching the porous medium identification and their control on the reservoirs based on case studies (BENZAGOUTA, M . S. and LEE, M . R ., 1991), (Benzagouta, M. S. and Amro, M. M., 2009), (Kharraa, H. S. et Al., 2013), (Attia, M.M., Abudeif, A.M., Radwan, A.E., 2015). However, permeability can also be determined from core data, as it can be estimated from N.M.R. and well test interpretation. Similar operating processes are mainly used during the exploration and evaluation activities. Drill Stem Test (DST) and Wire Line Formation Tester (RFT/MDT/XPT/RCI) constitute the principal devices for outcomes. Development activities such as pressure transient testing can also be a close part of the investigation (Belhouchet, H. E. and Benzagouta, M. S., 2019).

Within the porous medium, identification of the stored fluid type is also required, to evaluate fluid volume. In oil and gas industry exploration and production, several techniques were worked out to define fluid type, its location and level of contact. Data coming out from well logs such as NMR, resistivity, density and neutron logs, combined with MDT pressure measurements and fluid samples, yield positive identification of formation fluids type. Additionally the outcomes are allowing determining the oil - water contact (O.W.C.) as well oil - gas contact (O. G.C.), and gas - water contact (G.W.C.) (Abudeif, A. M. et Al., 2018). It is important to mention the distinction between the FWL (free water level) is generally not matching the OWC (oil water contact): they differs by an amount related to the displacement pressure (Elshahawi, H. et al., 1999).

The investigation applied in our case study was through Wireline formation tester (WFT) which is introduced to the oil industry in 1955 (Conrad, K. M., 1962). It was conducted to estimate key parameters such as initial reservoir pressure, local permeability and reservoir fluid type (Abudeif, A. M. et Al., 2018). Support in that circumstances is from (Dubost, F. X. et al., 2007) and (Elshahawi, H. et al., 1999). The use of these parameters can be essential resources for conducting research on the preferential fluid flow stored within the porous medium and furthermore exploring the possibility of perceiving permeability barriers.

Different tools can be used for the purpose of fluid behavior related to the porous medium. Repeat Formation Test (RFT), Reservoir Characterization Instrument (RCI), Modular Formation Dynamics Tester (MDT) and Formation Pressure test $\log$ (XPT) are formation tester and sampling tools. They record the formation pressure versus depth at various interval points in the open hole using a wire-line. These tools are also aimed to collect fluid samples (Dybdahl, B. and Hjermstad, H. P., 2001), (Radwan, A. E. et Al., 2020).

In our case investigation and among the previously identified devices, it is the modular dynamic tester (MDT) which has been in use. The concerned tool was conducted for formation evaluation of pressure, temperature, and reservoir quality. One of its aims is the full understanding of the static and dynamic reservoir behavior (Worthington, P. F. et AL., 2012). Formation pressure analysis is very interesting to approach. It is useful in providing information on reservoir quality and compartmentalization (James Howes, 1999). The MDT is correspondingly an accurate tool for delivering statements on reservoir fluid type and free water level (FWL) (Belabed, Malik, 2017).

At the present time, the use of the MDT tool has become indispensable for the development of the oil and gas fields because it provides basic information on the type and number of reservoir fluids and their contacts. The vertical recording made by the MDT provides pressure and mobility measurements at 
specific points, chosen according to the log interpretation (Burnie, S. W., and Chen, Z. A., 1998). For accurate readings, points with low mobility and huge values are automatically eliminated. Their removal is own to problems related to the supercharged phenomenon, coupled to severe petrophysical characteristics, degradation, tightness, with sensor blockage (Proett, M. A. and Waid, M. C. , 1997) and (Basioni, M. A. et Al., 2012). Own to accurate representative, and indicative pressure gradients, the elimination of non-significant points, along the concerned reservoir section, must be necessary to state.

In this investigation, the use of pressure gradients is aimed to investigate on the communication between boreholes. Similar task will provide information on the reservoir depletion when drilling a well subsequent to certain production time (Bo Cribbs, 2009). Moreover, pressure gradient change analyses constitute an enhancing support for estimating the original hydrocarbon in place as well as the aquifer activity and assessment. Obtained gradients number will be characterizing fluids types based on their respective setting density values. Thus, a change in pressure gradient will be related to the change in the reservoir fluid type. Hence, the intersection between the two fluid gradients can be interpreted as a credible contact, separating two immiscible fluids in which capillary pressure should be zero. Similar statement is well supported by (Fawakhir, A.Y. et Al., 1989) and (Elshahawi, H. et al., 1999).

Application of the MDT, in the purpose of pressure determination and setting aimed to various gradients evolution, has become necessary for the case study. The pressure distribution is brought up to the well communication probe. Thus, lateral and vertical reservoir continuity and connectivity, with potential fluid contact determination constitute a key factor to be set in the reservoir. The use of data generated from the MDT can also be aimed to permit setting and extending limits for the free water level (F.W.L.) respective for each borehole composed zones. Related tasks will allow finding out the free water level outspread with respect to the surrounding boreholes. Similar outcomes will conduct reaching an overview concerning reservoir heterogeneity. Therefore, the basis of this investigation is stressing on a framework for reservoir compartmentalization in multilayer reservoirs. Therefore, the main objectives of this case study can be set according to available data generated from the MDT as:

- Determination of unconnected reservoir layers.

- Identification of reservoir fluid types and fluid gradient contact setting.

- Determination of fluid type regions.

- Determination of the free water level (F.W.L.) and the identification of the referred pressure.

Application of this investigation is conducted towards some of the Hassi Berkine oil field reservoirs (Algeria). As the concerned reservoirs are involved with similar ambiguous states.

\section{GEOLOGICAL SETTING}

The Hassi Berkine field was discovered in January 1995 by the SONATRACH/ANADARKO association (Lo, L.L. et Al., 2004). the Berkine Basin is located in south - eastern Algeria, between latitude 29 degrees and 33 degrees north and longitude 5 degrees and 9 degrees East (Belhouchet, H.E., Benzagouta, M.S. Dobbi,A. et Al., 2020). It is limited to the north by the southern border of the Dahar Mole, to the south by the Mole D'Ahara which separates it from the Illizi basin. The concerned basin is bounded to the East by the Tunisian - Libyan borders and finally to the west by the structural extension north of the Amguide - El Biode - Hassi Messaoud Mole. The Berkine Basin is a part of the northern margin of the Saharan platform. It is an intra - or pericratonic basin which has been developed during Middle-Late Triassic times (Turner, P. et Al., 2001) .

The main reservoir in this field is the Lower Triassic Clayey Sandstone (TAGI, French abbreviation for Trias Argilo-Gréseux Inferieur). The thickness of the TAGI varies from 65 meters to 130 meters. TAGI 
is of a transgressive nature and lies unconformably on the Paleozoic formations. It is mainly represented by fluvial and lacustrine deposits. Sometimes these deposits are interbedded by aeolian and deltaic layers. Based on the extensive core data and regional interpretation of wireline logs (Benamrane Oussalem, 1987), (Arezki Boudjema, 1987) the TAGI reservoir could be subdivided into three main levels; upper, middle and lower. These levels are subdivided into a total of nine layers (figure 1).

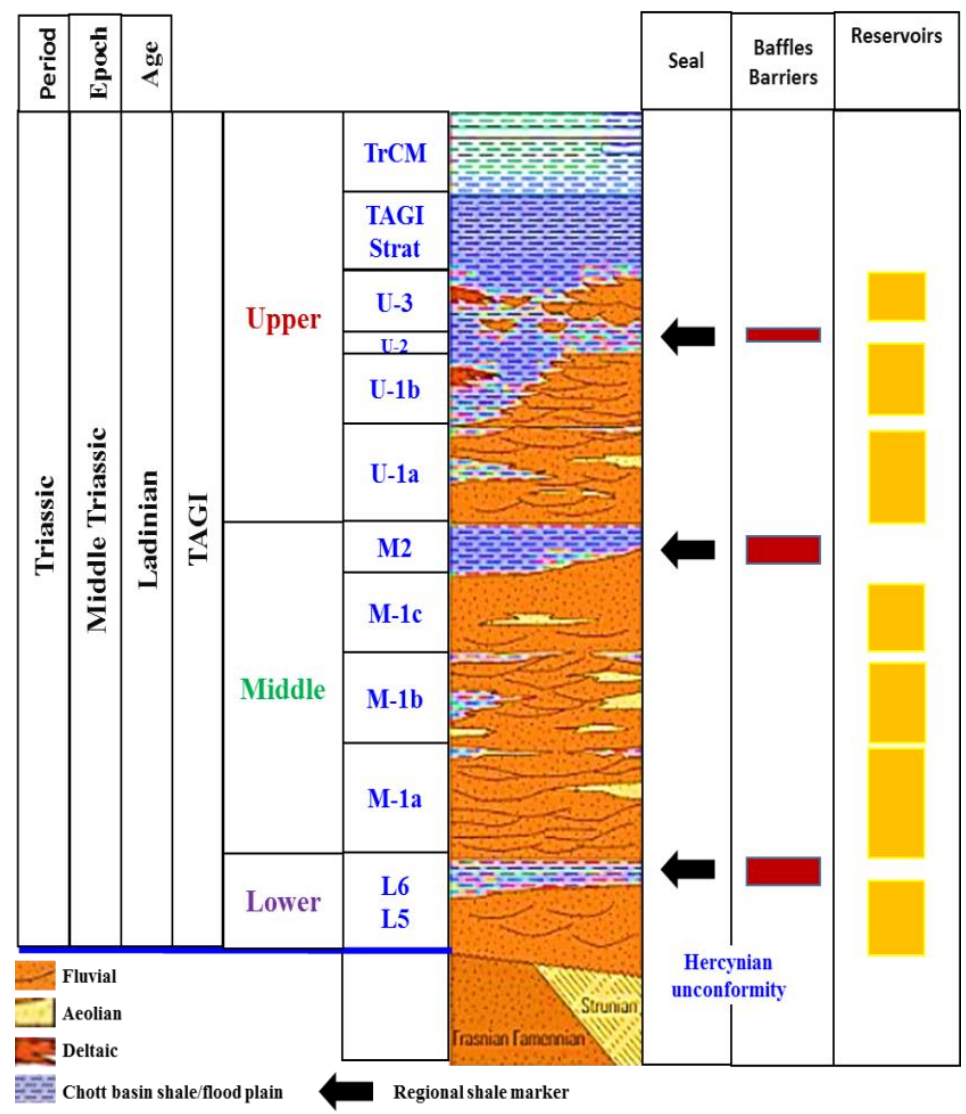

Figure 1: Reservoir subunits in TAGI (Sonatrach WEC, 2007)

Detailed sedimentological and stratigraphic subdivision of the TAGI is as follow is according to (Arezki Boudjema, 1987), (Hamid Aitt-Salem, 1990), (Sonatrach WEC, 2007) and (Sayed, A.E. and Bachagha, W. and Benzagouta, M.S., 2017).

The upper TAGI consisting of:

- U1 a sandstone level characterized by fluviatile deposits traversed by eolian deposits. This has a good lateral extension.

- U1b a sandstone level whose reservoir qualities deteriorate toward the southeast. It also includes some interbedded deltaic deposits.

- U2 is the clay which is assumed to be regionally continuous and characteristically has small thickness. It is also marked by lacustrine deposits.

- U3 of variable thickness, in which the first sandstone beds interbedded with deltaic deposits are encountered.

The middle TAGI is subdivided into four levels: 
- M2 clayish unit, which is assumed to be a lacustrine deposit and of regional extent. It is of very variable thickness.

- M1c, M1b, and M1a, which are sandstone having generally good reservoir characteristics. They are marked by variable thicknesses according to the local distribution of channels. Level M1 shows the greatest variation in thickness.

The lower TAGI, which lies directly on the hercynian unconformity, is subdivided into two levels

- $\quad$ L5 a sandstone characterized by fluviatile deposits.

- L6 representing the clay.

In the conducted case, an investigation is concerned with TAGI formation assembling three wells: well1, well-2 and well-3 belonging to the Hassi Berkine basin (figure 2). The reservoir characteristics analysis has been found of relatively up to good quality porosity. It is varying from 7 to $20 \%$ whereas the permeability is found fluctuating from 1 millidarcies to 850 millidarcies $(\mathrm{mD})$ (Belhouchet, H.E., Benzagouta, M.S. Dobbi,A. et Al., 2020). The initial development plan called a first stage of production during the first 5 years was at the rate of $5000 \mathrm{Stb} /$ day. This production is supported by water injection at the reservoir peripheral. Initial well tests carried out on the well-2 were indicator of an excellent sandstone reservoir (TAGI) with a flow of $4500 \mathrm{Stb} /$ day. It is important to mention that no water cut (WCT) has been observed.

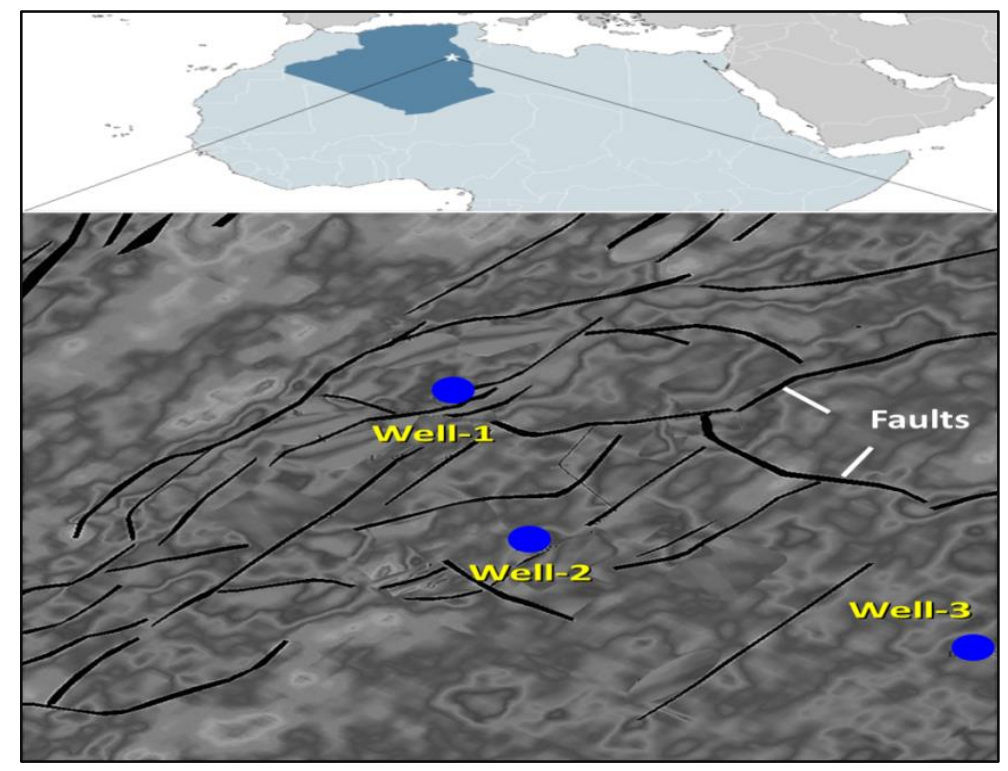

Figure 2: Wells position map

\section{MATERIAL AND METHODOLOGY OF INVESTIGATION}

Interest in the case study area were wells 1, 2 and 3 drilled in the area of Hassi Berkine oilfield basin (figure 2). Available data includes pressure data recorded using Modular Formation Dynamics Tester (MDT) or Formation Pressure Tester Tools (F.P.T.T.). These tools are aimed to provide along the concerned reservoir section, pressure and mobility measurements. The recorded data is established at specific selected points, according to the well log interpretation.

The number of selected points could be depending on the thickness of the reservoir layer. According to the tool efficiency (MDT) in the case study, four to six points can be selected for each reservoir layer, 
depending on the tasks. Restriction in this methodology procedure is to automatically eliminate data with low or huge mobility values. This task is intended to avoid supercharged phenomenon such as: severe petrophysical characteristics degradation, tightness and the sensor blockage. The elimination of non-significant points must be necessary to have a representative and indicative pressure measurements and gradients. Table (see \#Appendix) is indicator of the considered data in that purpose.

Conducted investigation can be referred to reservoir pressure parameter. This considered factor can be a useful device in indicating a static linear-gradient contingent on the fluid's density (water, brines, oil, and gas) in the pore spaces (Selim S. Shaker, (2012). Support in that purpose can be through the pore pressure of the reservoirs (Radwan, A. E. et Al., 2019). Stated equations are as follow:

$$
P_{z}=0.433 * \text { Fluid Density } * Z
$$

Thus, the gradient can be calculated by Fooshee, Jeffrey Steven, 2009:

$$
\text { Fluid Gradient }(p s i / f t)=\frac{P_{Z}}{Z}=0.433 * \text { Fluid Density }
$$

$P_{z} ;$ Pressure at depth

$\mathrm{Z}$; Depth

Using the equation (2), the fluid density can be calculated based on gradient observed graphically according to the following formula:

$$
\text { Fluid Density }=\text { Fluid Gradient/0.433 }
$$

Oil-field liquids and gases occur in a wide range of compositions. The table below shows typical density ranges and gradients for gas, oil, and water. However, own to exceptions occurrences, some expected fluid types might present their own appropriate values (Fooshee, Jeffrey Steven, 2009). Thus, fluid density outcomes in our case study can be derived from (Table 1).

\begin{tabular}{|c|c|c|}
\hline Fluid & Normal Density range $(\mathbf{g} / \mathbf{c m 3})$ & Gradient (psi/feet) \\
\hline Gaz (Gazeux) & $0.007-0.3$ & $0.003-1.13$ \\
\hline Gaz (liquide) & $0.2-0.4$ & $0.09-0.174$ \\
\hline Oil & $0.4-1.2$ & $0.174-0.486$ \\
\hline Water or Brine & $1-1.15$ & $0.433-0.50$ \\
\hline
\end{tabular}

Table 1: Table showing the fluid density and Gradient ranges for different fluids (AAPG WIKI, 2015)

\section{RESULTS AND INTERPRETATION}

In order to calculate the pressure gradients at the wells drilled from the MDT data, quality control of the recorded points must be carried out. The led process for the case study was based on the pressure quantity recorded in relation to the actual pressure. The oversized pressures have been eliminated automatically. This subtraction depends on the measured mobility: Specifically points of low mobility, their occurrence can be own to the degradation of petrophysical characteristics. The dimensionless mobility points were related to the presence of fractures or sealing problems. These two cases of mobility; minimal and dimensionless were directly eliminated. The remaining points have constituted the most representative measurements. They afford a better illustration of the pressure gradients giving a possibility to identify the static and dynamic reservoir behaviors. According to the MDT obtained results for the case study, three main interpretation steps were set. 


\section{A. Determination of unconnected reservoir layers and reservoir fluid type}

The first step consists of locally processing the MDT records. The obtained data from exploration wells are intended to determine the number of unconnected reservoir layers and identify the type of reservoir fluid. Different boreholes were considered in the purpose of obtaining maximum information on fluid distribution and contact in addition to reservoir heterogeneities (Belhouchet, H.E., Benzagouta, M.S. Dobbi,A. et Al., 2020).

\section{1) WELL-1}

Well-1 is the first exploration well drilled in the north west of the field. The well location and pressure reordered from formation pressure tester (MDT) are illustrated in figure 3. Results and interpretation, based on formation pressure tester, for the case study, have been found very significant towards reservoir type. Different compartments were defined on the basis of pressure versus depth (figure 3). Using this tool, in the case study, is own to its performance in that considered topic (Noah, A. Z., 2014). The acquired compartments revealed more useful information on the possible heterogeneities of the reservoir, which can be closely related to the presence of a number of permeability barriers (figure 4).

According to the graphical analysis, with pressure versus depth, several pressure gradients with statistically significant trends have been found, for the same considered well (figure 3). The range of pressure gradients occurring in the first exploration well might be related to the presence of two distinct reservoir layers being separated by shale barriers (figure 4). Based on graphical interpretation, with pressure versus depth, three pressure gradients were defined: $0.34 \mathrm{psi} / \mathrm{feet}$ in the upper TAGI, 0.47 psi/feet in the middle TAGI and $0.3 \mathrm{psi} /$ feet in the lower TAGI. In order to estimate the equivalent density, equation 3 was applied. Depending on the results obtained, the reservoir layers were characterized by three different reservoir fluids based on their specific density: the first fluid with a density of $0.78 \mathrm{~kg} / \mathrm{l}$ in TAGI-U, in TAGI-M, the fluid characterized by a density of $1.08 \mathrm{~kg} / \mathrm{l}$, and the third fluid in TAGI-L with a density of $0.69 \mathrm{~kg} / \mathrm{l}$ (Table 2).

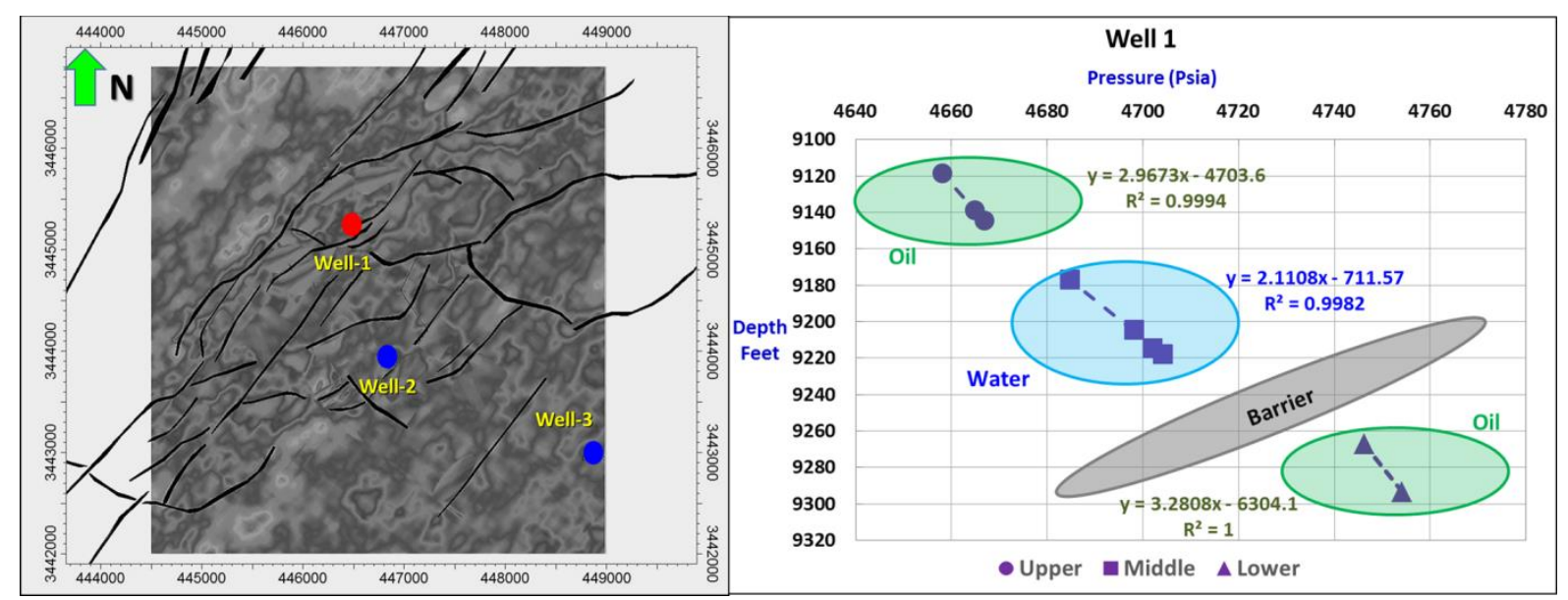

Figure 3: Well location and pressure reordered from formation pressure tester (MDT) for Well-1 


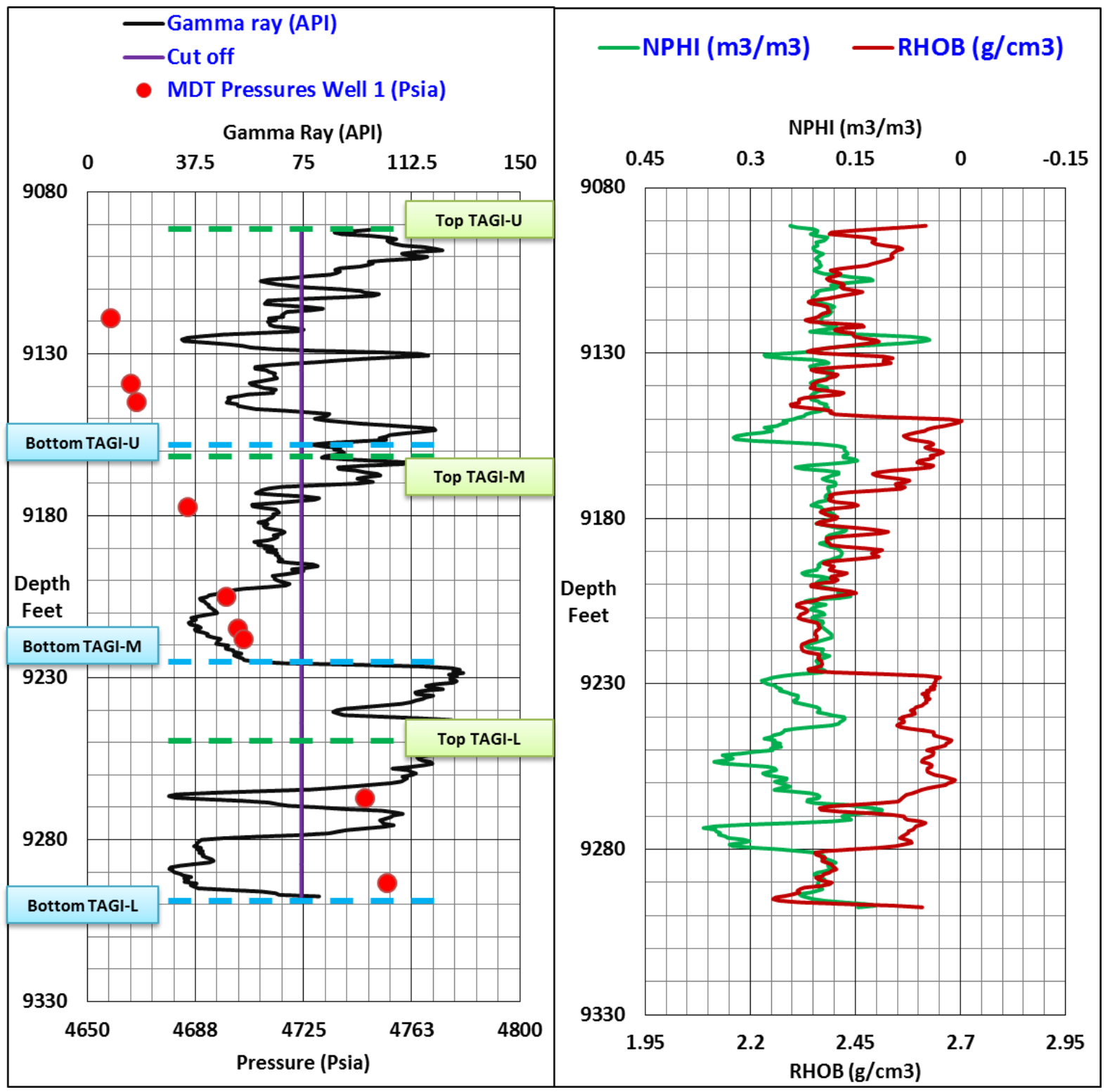

Figure 4: Well logs; Gamma ray, RHOB and NPHI, including the MDT measurements in the Well-1

\begin{tabular}{|c|c|c|c|c|c|c|}
\hline Wells & Level & Gradient (psi/feet) & $\mathbf{d}(\mathbf{l b} / \mathbf{g a l})$ & $\mathbf{d}(\mathbf{k g} / \mathbf{m 3})$ & $\mathbf{d}(\mathbf{k g} / \mathbf{l})$ & Fluid \\
\hline WELL-1 & TAGI-U & 0.34 & 6.53846 & 783.48048 & 0.78 & Oil \\
\hline WELL-1 & TAGI-M & 0.47 & 9.03846 & 1083.04655 & 1.08 & Water \\
\hline WELL-1 & TAGI-L & 0.3 & 5.76923 & 691.30631 & 0.69 & Oil \\
\hline
\end{tabular}

Table 2: Pressure gradients and fluid densities interpreted for the Well-1

238 This well was drilled in the central part of the field with the aim of crossing all the reservoir sections 239 for collecting useful information, and to acquire pressure gradients in the desired area. The location of the concerned wells with the MDT records is shown in figure 5. 


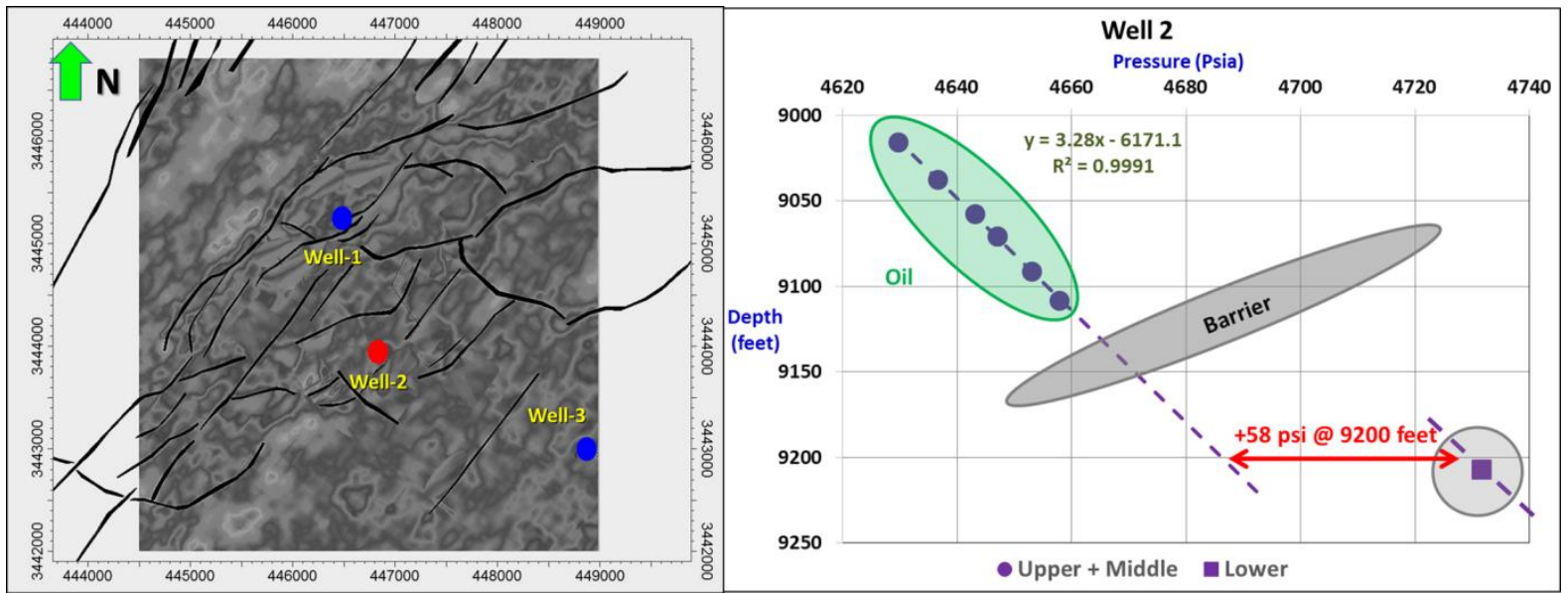

Figure 5: Well location and recorded pressure from formation pressure tester (MDT) for well-2

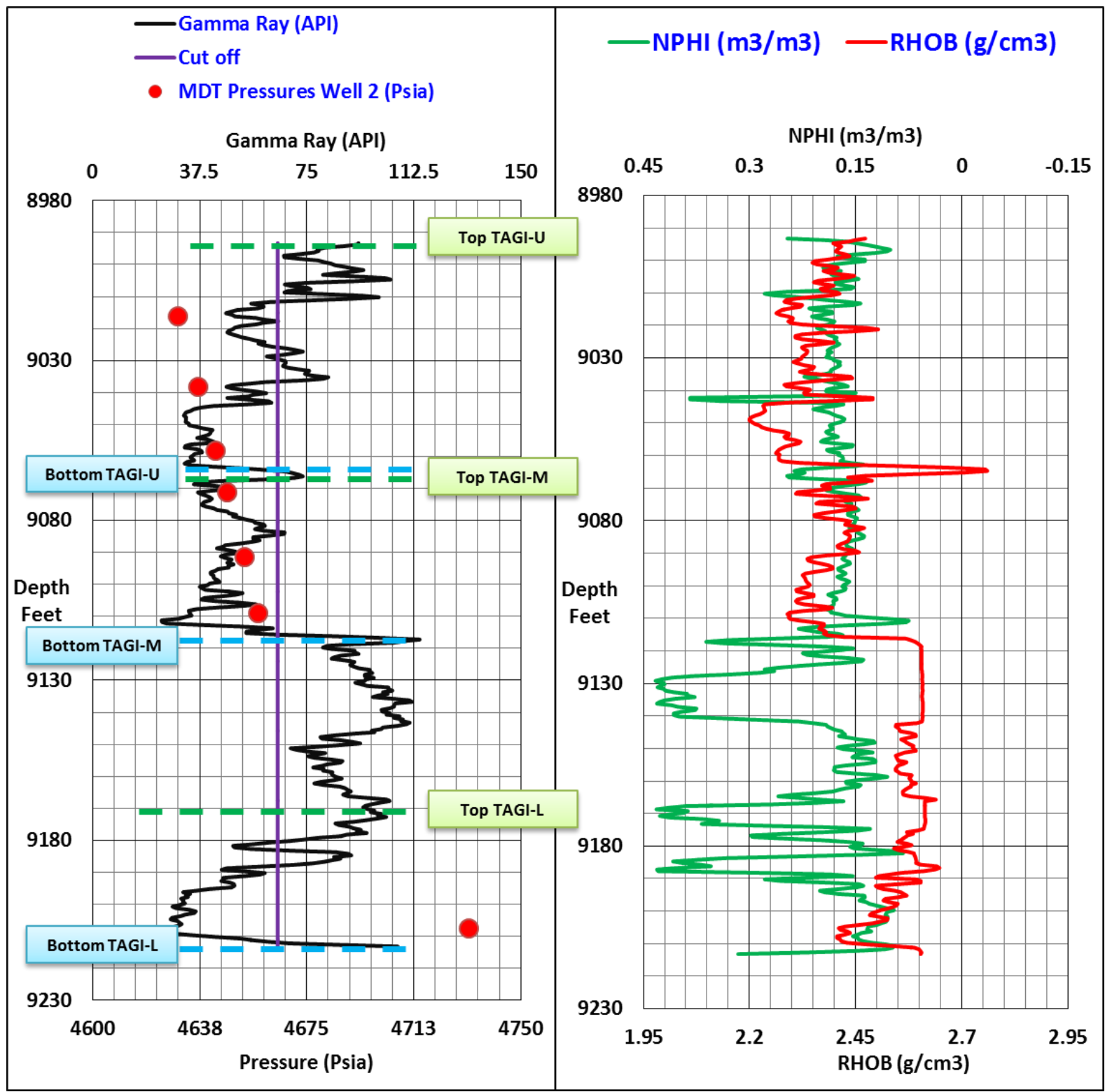

Figure 6: Well logs; Gamma ray, RHOB and NPHI, including the MDT measurements for Well-2 
Graphical analyses, using the formation pressure tester records, for well-2, revealed the same results as in well-1. Two separately gradients have been selected: first in the upper and middle reservoir part and the second gradient was pointing up along the lower considered reservoir section (figure 5). The pressure gradients, presented in the upper and middle reservoir sections, show that the fluid reservoir could be the oil according to the defined gradient $0.3048 \mathrm{Psi} /$ feet. This gradient is similar to that gradient observed in the TAGI-L (well-1), and therefore, the same fluid has been proven in the two reservoir levels TAGI U+M for the well-2 (table 3) and TAGI-L for the well-1 (table 2). Although the presence of a single point in the lower part of the reservoir gives information on the pressure dimension, but it remains insufficient for determining the pressure gradient for this reservoir level.

An identical gradient has been identified in the upper and middle reservoir sections (figure 5). It means that these upper and middle reservoirs can be treated as in dynamic communication. Assuming that, the same type of reservoir fluid was presented in the TAGI-L. Additionally and according to the gradient profiles passing through the points recorded in the TAGI U + M and the TAGI-L at depth -9200 feet, a difference of 58 Psi was observed between the Upper-Middle and Lower reservoir sections (figure 4). This distinction can be obviously related to the presence of a likely lithologic barrier between the two zones (figure 6).

\begin{tabular}{|c|c|c|c|c|c|c|}
\hline Wells & Level & Gradient (psi/feet) & $\mathbf{d}(\mathbf{l b} / \mathbf{g a l})$ & $\mathbf{d}(\mathbf{k g} / \mathbf{m 3})$ & $\mathbf{d}(\mathbf{k g} / \mathbf{l})$ & Fluid \\
\hline WELL-2 & TAGI-U & 0.3 & 5.76923 & 691.30631 & 0.69 & Oil \\
\hline WELL-2 & TAGI-M & 0.3 & 5.76923 & 691.30631 & 0.69 & Oil \\
\hline WELL-2 & TAGI-L & - & - & - & - & - \\
\hline
\end{tabular}

Table 3: Pressure gradients and fluid densities interpreted for the well-2

\section{3) WELL-3}

After confirmation of the presence of the two reservoir fluids, a third well has been proposed to be drilled in the aquifer zone. Among objective in that purpose was the topping of the free water level (F.W.L.) in both reservoirs; upper, middle and lower part. The location of the well and pressure reordered from formation pressure tester (MDT) is illustrated in figure 7.

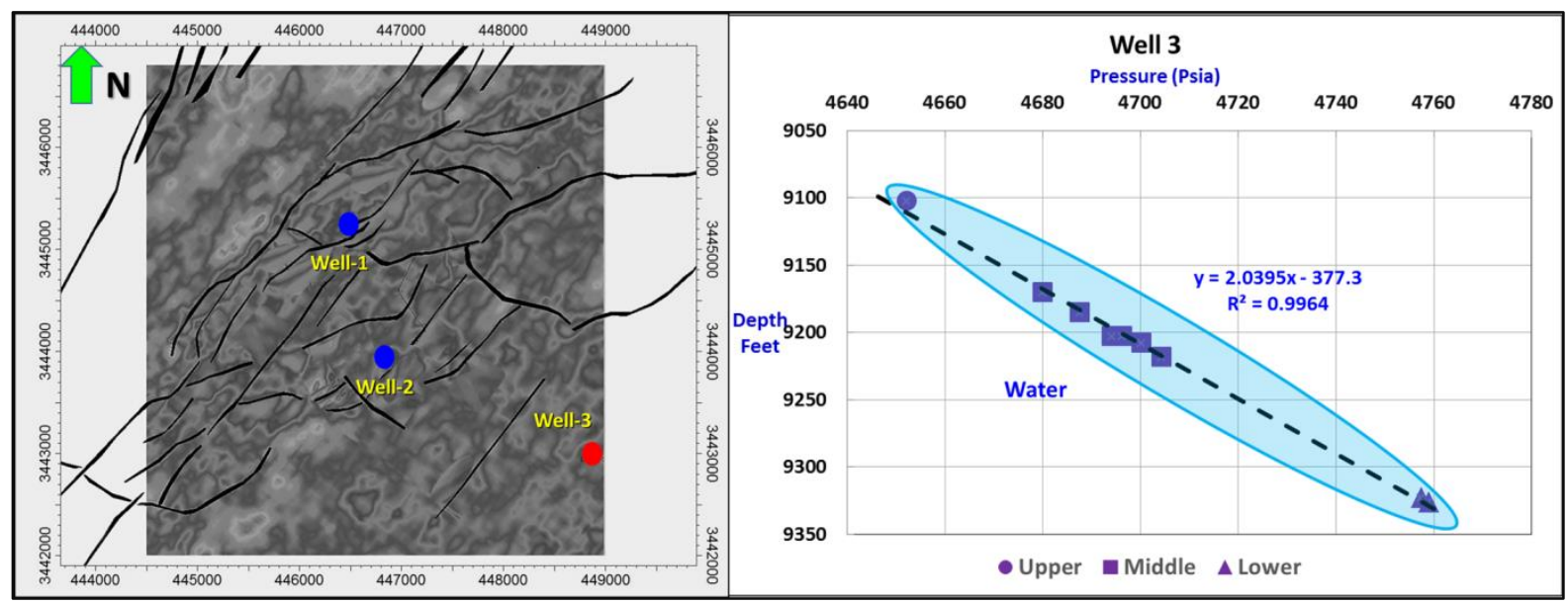

Figure 7: Well location and pressure reordered from formation pressure tester (MDT) for well-3 with 


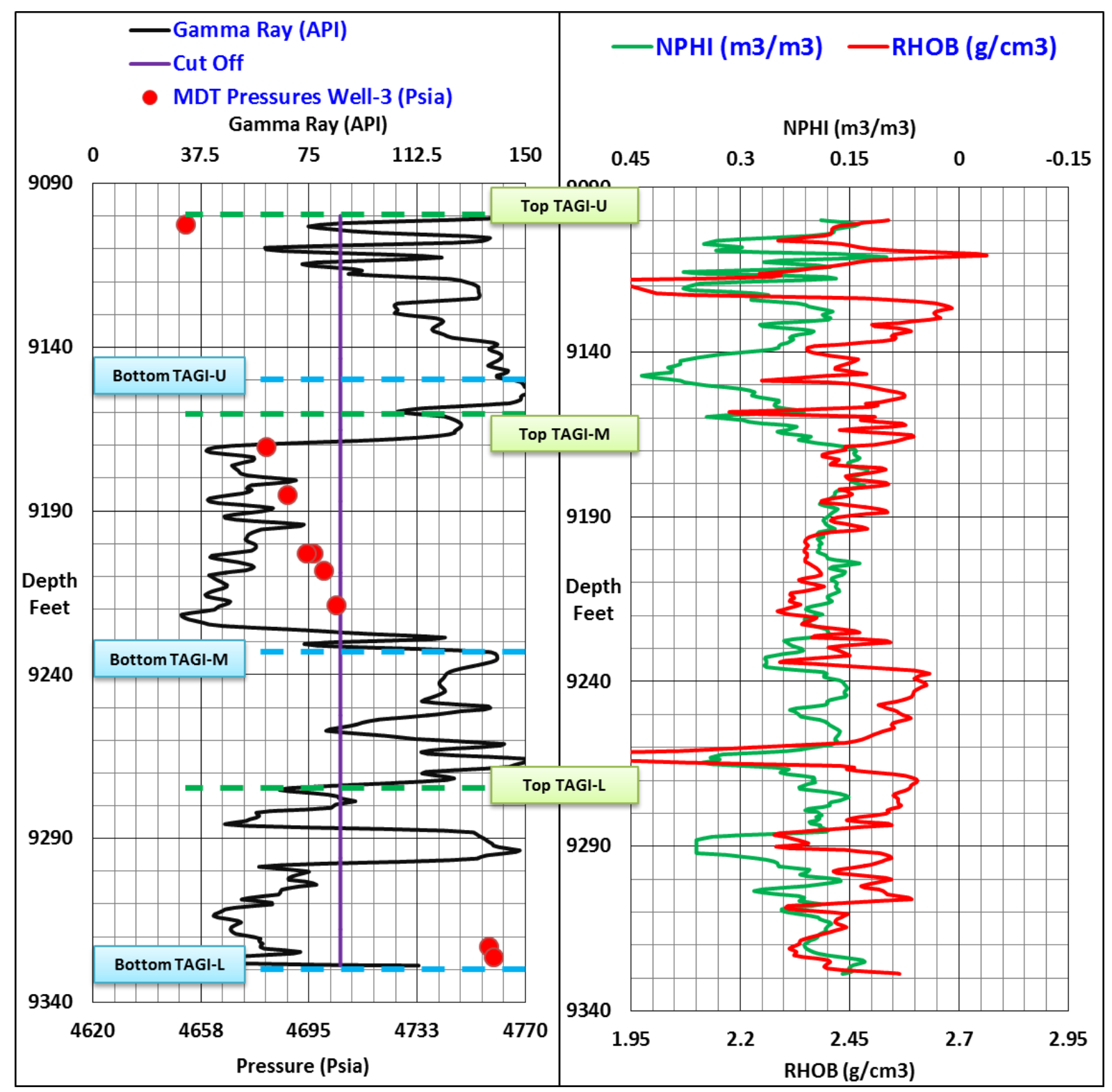

Figure 8: Well logs; Gamma ray, RHOB and NPHI, including the MDT measurements in the well-3

Regarding the figure 7, the formation pressure tester analysis (F.P.T.A.) shows the same pressure gradient profile for the upper, middle and lower reservoir sections. The implication of the gamma ray $\log$ is indicator of a stratigraphic barrier between these reservoir levels (figure 8). This statement can be, in terms of lithology, a stratigraphic barriers being revealed using well logs, Implication of pressure gradients which is the same, essentially in the TAGI-M and TAGI-L, is revealing that the three reservoir levels have been saturated by the same fluid type, a communication path is probable. Thus, the stratigraphic barrier is discontinuous or disjointed. The recorded pressure gradient in this well is about $0.51 \mathrm{psi} / \mathrm{ft}$. Similar value is corresponding to water fluid in table 4 . Thus, this is revealing that the drilled borehole reservoir is a water fluid type. Depending on the location of the aquifer zone in this considered borehole, recommended is to use its own specific data information for establishing the free water level (F.W.L.) and its extend. 


\begin{tabular}{|c|c|c|c|c|c|c|}
\hline Wells & Level & Gradient (psi/feet) & $\mathbf{d}(\mathbf{l b} / \mathbf{g a l})$ & $\mathbf{d}(\mathbf{k g} / \mathbf{m} 3)$ & $\mathbf{d}(\mathbf{k g} / \mathbf{l})$ & Fluid \\
\hline WELL-3 & TAGI-U & 0.51 & 9.80769 & 1175.22073 & 1.18 & Water \\
\hline WELL-3 & TAGI-L & 0.51 & 9.80769 & 1175.22073 & 1.18 & Water \\
\hline
\end{tabular}

Table 4: Pressure gradients and fluid densities interpretation for the well-3

286

287

288

289

290

291

292

293

294

295

296

297

298

299

300

301

302

\section{B. Fluid Type (PVT) Regions Identification}

Based on the pressure gradients defined in the previous section, the density of the reservoir fluid was calculated for each reservoir level. According to the obtained results, several reservoir fluid types have been expected. Similar results constitute the main support for going through reservoir compartmentalization. Thus, the need for the determination of the fluid type regions should be necessary.

An analytical examination of MDT pressure recorded is showing the presence of two oil gradients which are: $0.34 \mathrm{psi} /$ feet and $0.3 \mathrm{psi} / \mathrm{feet}$. Based on these gradients, the densities of reservoir fluids were calculated by applying the equation 3 . The first estimated density is $0.78 \mathrm{~kg} / \mathrm{l}$ in the upper TAGI located in the western zone of the field (well-1 zone). The second extracted density is $0.69 \mathrm{~kg} / \mathrm{l}$ corresponding to the lower TAGI, situated in the same zone (well-1 zone). The same density of $0.69 \mathrm{~kg} / \mathrm{l}$ has been obtained for TAGI U+M in the eastern zone (well-2 zone). In view of that results, two PVT regions were defined; PVT region 1 in the upper TAGI of the western area of the field (TAGI-U), and PVT region 2 in the lower TAGI of the western area, and TAGI $U+M$ for the eastern area of the field. For accurate support and statement deduction, summarized pressure gradients and estimated fluid density outcomes are sited in table 5.

\begin{tabular}{|c|c|c|c|c|c|c|}
\hline Wells & Level & $\begin{array}{c}\text { Gradient } \\
\text { (psi/feet) }\end{array}$ & $\begin{array}{c}\text { Fluid Density } \\
(\mathbf{l b} / \text { gal })\end{array}$ & $\begin{array}{c}\text { Fluid Density } \\
(\mathbf{k g} / \mathbf{m 3})\end{array}$ & $\begin{array}{c}\text { Fluid Density } \\
(\mathbf{k g} / \mathbf{l})\end{array}$ & $\begin{array}{c}\text { Fluid } \\
\text { Type }\end{array}$ \\
\hline Well-1 & TAGI-U & 0.34 & 6.53846 & 783.48048 & 0.78 & Oil \\
\hline Well-1 & TAGI-M & 0.47 & 9.03846 & 1083.04655 & 1.08 & Water \\
\hline Well-1 & TAGI-L & 0.3 & 5.76923 & 691.30631 & 0.69 & Oil \\
\hline Well-2 & TAGI-U & 0.3 & 5.76923 & 691.30631 & 0.69 & Oil \\
\hline Well-2 & TAGI-M & 0.3 & 5.76923 & 691.30631 & 0.69 & OIl \\
\hline Well-3 & TAGI-M & 0.51 & 9.80769 & 1175.22073 & 1.18 & Water \\
\hline Well-3 & TAGI-L & 0.51 & 9.80769 & 1175.22073 & 1.18 & Water \\
\hline
\end{tabular}

Table 5: Pressure gradients and deduced fluid densities for the considered case study boreholes

\section{Free Water Level and Reference Pressure Determination}

The third phase is effectively based on the general view of the field. It focuses mainly on exploiting the gradients measured at all exploration boreholes to determine the free water level (F.W.L.) and the referred pressure. The free water level identification (F.W.L.) is one of the main variables used to define the reservoir compartments. To determine the F.W.L., the use of M.D.T. data, prior to production starting-up, must be required essentially. The first step in this action is to interpret the formation pressure tester data to define reservoir compartments at each well. The graphical analysis of pressure gradients, measured and recorded from the two drilled wells (well-1 and well-2), has shown that TAGI reservoir could be subdivided, according to pressure profile, into two compartments: the first compartment corresponds to the upper - middle reservoir section, whereas the second compartment can be allocated to the lower part (figures 3 and 5). 
The combination of the different pressure gradients versus depth, derived from the various neighboring boreholes, permit the set of the free water level (F.W.L.) at each considered reservoir. The graphical analysis of the formation pressure tester data shows the presence of two possible free water levels, the first one is located in the upper - middle TAGI and has been set at -9147.5 feet, and the second in the lower TAGI is expected at -9360.6 feet (figure 9). For precision, pressure equation parameters, used for F.W.L. determination for TAGI reservoir levels, are illustrated in tables 6 and 7.

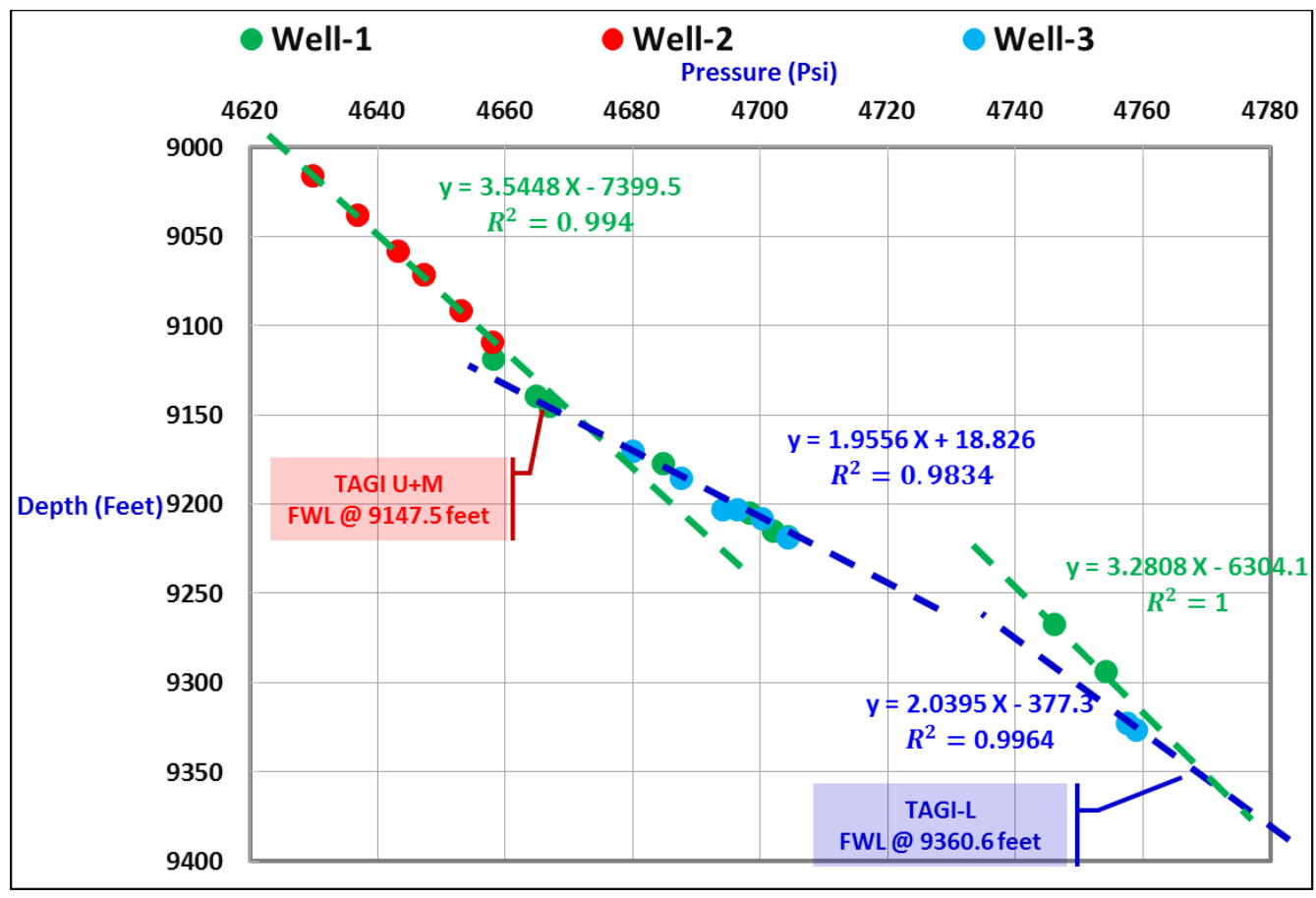

Figure 9: Formation pressure tester results recorded in the upper - middle and lower TAGI reservoirs of the exploration wells

\begin{tabular}{|c|c|c|c|}
\hline \multicolumn{3}{|c|}{ TAGI U+M } \\
\hline \multicolumn{2}{|c|}{ Oil equation } & \multicolumn{2}{c|}{ Water equation } \\
\hline $\mathbf{A}$ & 3.5448 & $\mathbf{A}^{\prime}$ & 1.9556 \\
\hline B & -7399.5 & $\mathbf{B}^{\prime}$ & 18.826 \\
\hline
\end{tabular}

Table 6: Pressure equation parameters used for F.W.L. determination for TAGI U+M

\begin{tabular}{|c|c|c|c|}
\hline \multicolumn{3}{|c|}{ TAGI-L } \\
\hline \multicolumn{2}{|c|}{ Oil equation } & \multicolumn{2}{c|}{ Water equation } \\
\hline $\mathbf{A}$ & 3.2808 & $\mathbf{A}^{\prime}$ & 2.0395 \\
\hline B & -6304.1 & $\mathbf{B}^{\prime}$ & -377.3 \\
\hline
\end{tabular}

Table 7: Pressure equation parameters used for F.W.L. determination for TAGI-L

Regarding the well gradients observed in the two wells (1 and 2), the pressure gradients characteristics are superimposed with a slight deviation. This change in gradient can be explained by the possible petrophysical characteristics degradation affecting differentially those two wells. It can also be related to the change in reservoir fluid type, especially in the TAGI-U. In terms of pressure similarities, these wells may suggest a scenario of being in a dynamic communication (table 8). 
Similar graphical results have allowed the estimation of the initial pressure for each reservoir layer respectively: 4668 Psi in upper and middle sections and 4775 Psi in the lower section (table 8).

\begin{tabular}{|c|c|c|}
\hline Regions & FWL (feet) & Reference Pressure (Psi) \\
\hline TAGI U (East Zone) + TAGI M & 9147.5 & 4668 \\
\hline TAGI U (West Zone) & 9147.2 & 4668 \\
\hline TAGI- L & 9360.6 & 4775 \\
\hline
\end{tabular}

Table 8: Reference Pressures, free water level and reservoir regions

\section{CONClusion}

Modular dynamic tester (MDT), in relation to pressure evolution versus depth, constitutes a useful tool to be used efficiently in order to split up the limit between the different fluids, stored in the porous medium. Variation in pressure gradient is an interesting parameter being collected and used for information regarding fluid characteristics type and possibly lithology nature. These pressure gradients were also an adequate device to reveal the possible dynamic communication between the boreholes. In addition, modular dynamic tester was a successful device to set gradients change aimed to especially establish not only the different fluid contacts including the free water level (F.W.L.) but also the vertical and lateral ambiguities regarding fluid dynamism and heterogeneities.

The prediction of the type, number and physical characteristics of the reservoir fluid, and initial reservoir pressure by MDT tools constitute the main factors for the surface facilities aspects.

Reservoir compartments, reference pressure, free water level, PVT regions determination are the main inputs for reservoir model initialization. The overall has got a significant impact on the quality of simulation results.

The determination of the free water level (F.W.L.) reflects the initial conditions of the field that have a very significant impact on the estimation of the original oil in place (OOIP). Accordingly, this F.W.L. can be considered as one of the main factors involved for the field development plan preparation.

\section{FUNDING SOURCES}

The authors engaged themselves to declare that they have no known competing financial interests or personal relationships that could have appeared to influence the work reported in this paper.

\section{CONFLICT OF INTEREST STATEMENT}

The authors have no conflict of interest to report.

\section{REFERENCES}

AAPG WIKI. (2015, February 24). Retrieved from

https://wiki.aapg.org/Normal_hydrostatic_pressure_gradients.

Abudeif, A. M. et Al. (2018). Hydrocarbon type detection using the synthetic logs: A case study, Baba member, Gulf of Suez, Egypt. Journal of African Earth Sciences, Volume 144, p. 176-182.

Arezki Boudjema. (1987). Évolution structurale du bassin pétrolier "triasique" du Sahara Nord oriental (Algérie). Thèse de doctorat en Terre, Océan, Espace, Paris. 
Attia, M.M., Abudeif, A.M., Radwan, A.E. (2015). Petrophysical analysis and hydrocarbon potentialities of the untested Middle Miocene Sidri and Baba sandstone of Belayim Formation, Badri Field, Gulf of Suez, Egypt. Journal of African Earth Sciences, Volume 109, pp 120-130.

Basioni, M. A. et Al. (2012). A Case Study on Compositional Reservoir Simulation for a large Tight Reservoir: A Detailed Road Map from Initialization and History Match to Prediction Simulation. North Africa Technical Conference and Exhibition. Cairo, Egypt: Society of Petroleum Engineers.

Belabed, Malik. (2017). Gas-Water Contacts, Free Water Levels analysis in support of petroleum exploration in offshore Netherlands.

Belhouchet, H. E. and Benzagouta, M. S. (2019). Rock Typing: Reservoir PermeabilityCalculation Using Discrete RockTyping Methods (DRT): Case Studyfrom the Algerian B-H Oil Field Reservoir. In Banerjee S., Barati R., Patil S., Advances in Petroleum Engineering and Petroleum Geochemistry. CAJG 2018 (pp. pp 9 - 12).

Belhouchet, H.E., Benzagouta, M.S. Dobbi,A. et Al. (2020). A new empirical model for enhancing well log permeability prediction, using nonlinear regression method: Case study from HassiBerkine oil field reservoir - Algeria. Journal of King Saud University - Engineering Sciences, https://doi.org/10.1016/j.jksues.2020.04.008.

Benamrane Oussalem. (1987). DIAGRAPHIES ET SEDIMENTOLOGIE. UNE COMBINAISON EFFICACE POUR L'ETUDE DES BASSINS ET L'EXPLORATION DES PIEGES STRATIGRAPHIQUES D'HYDROCARBURES : APPLICATION AU TRIAS DU BASSIN DE OUED MYA - ALGERIE. [S.I.] : [s.n.].

BENZAGOUTA, M . S. and LEE, M . R . (1991). New evidence for the origin of distinctive quartz overgrowth textures in the Raisby Formation (Zechstein carbonate), north-east England. Proceedings of the Yorkshire Geological Society, VOL 48, PART 4, PP. 409-414.

Benzagouta, M. S. and Amro, M. M. (2009, May 9-11). Pressure and Temperature Effect on Petrophysical Characteristics: Carbonate Reservoir Case. SPE Saudi Arabia Section Technical Symposium, Al-Khobar, Saudi Arabia.

Benzagouta, M.S. et al. (2001). Reservoir Heterogeneities, in Fractured Fluvial Reservoirs of the Buchan Oilfield (Central North Sea). Oil \& Gas Science and Technology - Rev. IFP, Vol. 56 (2001), No. 4, 327 - 338.

Bo Cribbs. (2009). Practical Wellbore Formation Test Interpretation. Geoscience Technology Workshop, AAPG . Houston, Texas.

Burnie, S. W., and Chen, Z. A. (1998). MDT/RFT Pressure Testing: Reservoir Interpretation, Supercharging Evaluation, and Data Processing. Canadian Society of Petroleum Geologists.

Conrad, K. M. (1962). APPLICATION OF THE WIRELINE FORMATION TESTER. SPE Drilling and Production Practices Conference. Beaumont, Texas : Society of Petroleum Engineers. 
Dubost, F. X. et al. (2007). Integration of In-Situ Fluid Measurements for Pressure Gradients Calculations. Society of Petroleum Engineers.

Dybdahl, B. and Hjermstad, H. P. (2001). A systematic Approach to Sampling during Well Testing. SPE Latin American and Caribbean Petroleum Engineering Conference, 25-28 March, Buenos Aires, Argentina.

Elshahawi, H. et al. (1999, October 3-6). Capillary Pressure and Rock Wettability Effects on Wireline Formation Tester Measurements. Society of Petroleum Engineers, 16.

Fawakhir, A.Y. et Al. (1989). Procedures for Initializing Reservoir Simulation Models. SPE Middle East Oil Technical Conference and Exhibition (pp. pp 875 - 885). Manama, Bahrain: Soaiety of Petroleum Engineers.

Fooshee, Jeffrey Steven. (2009). The development of a pore pressure and fracture gradient prediction model for the Ewing Banks 910 area in the Gulf of Mexico. Louisiana State University and Agricultural and Mechanical College: LSU Master's Theses. 3198.

Hamid Ait-Salem. (1990). Le Trias détritique de l'Oued Mya (Sahara algérien) : sédimentation estuarienne, diagenèse et porogenèse, potentialités pétrolières. Thèse de doctorat dirigée par Elmi, Serge Sciences. Sédimentologie Lyon 11990.

Hongqi Liu. (2017). Principles and Applications of Well Logging. Beijing, China: Springer Mineralogy.

James Howes. (1999). WFT Data and Pressure Profile Analysis: Applications, Complexities, and Challenges. Conference: 27th Annual Convention Indonesian Petroleum Association, Volume: 1. Jakarta, Indonesia.

Kharraa, H. S. et Al. (2013). Assessment of Uncertainty in Porosity Measurements Using NMR and Conventional Logging Tools in Carbonate Reservoir. SPE Saudi Arabia section Annual Technical Symposium and Exhibition. Khobar, Saudi Arabia,: Society of Petroleum Engineers.

Lo, L.L. et Al. (2004). Application of the Novel Miscible Interpretation of RST Data and the WAG Pilot Results in Reservoir Simulation for Hassi Berkine South Field. SPE/DOE Symposium on Improved Oil Recovery. Tulsa, Oklahoma: Society of Petroleum Engineers.

Noah, A. Z. (2014). Use Repeat Formation Tester for Determination of Some Reservoir Characteristics for Kareem Formation in Some Wells at Amal Field, Gulf of Suez Area, Egypt. American Journal of Research Communication, Vol 24, pp. 157 - 167.

O. Serra. (1984). Fundamentals of Well Log Interpretation. Amsterdam, The Netherlands: ELSEVIER SCIENCE.

Proett, M. A. and Waid, M. C. . (1997). Patent No. 5,644,076. United States Patent.

Radwan, A. E. et Al. (2019). Pore and fracture pressure modeling using direct and indirect methods inBadri Field, Gulf of Suez, Egypt. Journal of African Earth Sciences, pp 133 - 143. 
Radwan, A. E. et Al. (2020). Geopressure Evaluation Using Integrated Basin Modelling, Well-Logging and Reservoir Data Analysis in the northern part of the Badri oil field, Gulf of Suez, Egypt. Journal of African Earth Sciences.

Sayed, A.E. and Bachagha, W. and Benzagouta, M.S. (2017). Caractérisation lithologique et pétrophysique (méthode analogique et IP) D'un niveau réservoir Trias Argileux Gréseux Supérieur", Master degree, . University of Oum Bouaghi Algeria.

Selim S. Shaker. (2012). Reservoir vs. Seal Pressure Gradients: Perception and Pitfalls - Based on Case Histories from the Gulf of Mexico. Canadian Society of Exploration Geophysicists, Vol. 37, Issue No. 04, pp. 31 - 41.

Sonatrach WEC. (2007). Well Evaluation Conference (WEC) Algeria 2007.

Tarek AHMED, e. P. (2005). Advanced Reservoir Engineering. 200 Wheeler Road, Burlington, MA 01803, USA: Elsevier Inc.

Turner, P. et Al. (2001). Sequence stratigraphy and sedimentology of the late Triassic TAG-I (Blocks 401/402, Berkine Basin, Algeria). Marine and Petroleum Geology, Volume 18, Issue, Pages 959 - 981.

Well Testing \& Fluids Sampling - Daleel. (n.d.). Retrieved from https://www.scmdaleel.com/category/well-testing-amp-fluids-sampling/23

Worthington, P. F. et AL. (2012). Optimizing the Value of Reservoir Simulation through Quality Assured Initialization. Society of Petroleum Engineering. Perth, Australia. 


\begin{tabular}{|c|c|c|c|c|c|}
\hline Wells & Depth (feet) & $\begin{array}{l}\text { Pressure } \\
\text { (Psia) }\end{array}$ & Mobility & Observation & Formation \\
\hline Well-1 & 9108 & - & - & Supercharging & TAGI-U \\
\hline Well-1 & 9119 & 4658 & 5.42 & representative & TAGI-U \\
\hline Well-1 & 9139 & 4665 & 35.01 & representative & TAGI-U \\
\hline Well-1 & 9145 & 4667 & 145.05 & representative & TAGI-U \\
\hline Well-1 & 9177 & 4685 & 7.55 & representative & TAGI-M \\
\hline Well-1 & 9205 & 4698 & 82.36 & representative & TAGI-M \\
\hline Well-1 & 9215 & 4702 & 42.6 & representative & TAGI-M \\
\hline Well-1 & 9218 & 4704 & 51.9 & representative & TAGI-M \\
\hline Well-1 & 9267 & 4746 & 65.3 & representative & TAGI-L \\
\hline Well-1 & 9289 & 5656 & - & $\begin{array}{l}\text { Oversized Pressure - } \\
\text { Not representative }\end{array}$ & TAGI-L \\
\hline Well-1 & 9294 & 4754 & 13.56 & representative & TAGI-L \\
\hline Well-2 & 9016 & 4630 & 72.63 & representative & TAGI-U \\
\hline Well-2 & 9038 & 4637 & 250 & representative & TAGI-U \\
\hline Well-2 & 9058 & 4643 & 180 & representative & TAGI-U \\
\hline Well-2 & 9071 & 4647 & 68.21 & representative & TAGI-M \\
\hline Well-2 & 9071 & 4647 & 7.06 & representative & TAGI-M \\
\hline Well-2 & 9092 & 4653 & 14.32 & representative & TAGI-M \\
\hline Well-2 & 9109 & 4658 & 21.34 & representative & TAGI-M \\
\hline Well-2 & 9201 & - & - & Supercharging & TAGI-L \\
\hline Well-2 & 9207 & 4732 & 35.2 & representative & TAGI-L \\
\hline Well-3 & 9103 & 4652 & 0.34 & Tight & TAGI-U \\
\hline Well-3 & 9114 & - & - & Supercharging & TAGI-U \\
\hline Well-3 & 9171 & 4680 & 9.4 & representative & TAGI-M \\
\hline Well-3 & 9185 & 4688 & 37.26 & representative & TAGI-M \\
\hline Well-3 & 9203 & 4694 & 16.34 & representative & TAGI-M \\
\hline Well-3 & 9203 & 4696 & 67.35 & representative & TAGI-M \\
\hline Well-3 & 9208 & 4700 & 195.64 & representative & TAGI-M \\
\hline Well-3 & 9219 & 4704 & 189.4 & representative & TAGI-M \\
\hline Well-3 & 9308 & - & - & Supercharging & TAGI-L \\
\hline Well-3 & 9323 & 4758 & 27.5 & representative & TAGI-L \\
\hline Well-3 & 9326 & 4759 & 6.5 & representative & TAGI-L \\
\hline
\end{tabular}

Table showing the quality control of MDT pressure records in the exploration wells 